En este sutil entramado en el que irrumpen estas figuras como momentos de una trayectoria de aprendizaje, la mirada acaba por establecerse como pacto de origen de la lectura y, finalmente, la síntesis de lo aprendido se pondrá a prueba en la emergencia de un momento autobiográfico como apertura hacia la puesta de manifiesto de este nuevo aprendizaje en la escritura.

Y como ocurría en sus clases, el libro pone al descubierto el aprendizaje de Germán como crítico pero también como escritor. Aquella clase que comenzaba con la anécdota de las baldosas, terminaba con una aseveración formulada en términos de convicción: «Y ustedes habrán podido ver a lo largo de esta clase, que yo ya decidí en cuál quiero quedarme». Las decisiones de Germán en términos de convicciones quedan expuestas en un texto en el que no sólo despliega una lectura reveladora de esta obra que lo apasiona, sino que logra movilizarnos en la mostración de su posición como crítico y lector. Una posición que no le teme a los trasluces de lo íntimo, y que por eso mismo, se muestra tan auspiciosa.

\title{
Apuntes sobre Sombras de autor. La narrativa latinoamericana entre siglos 19go-2010, de Carmen Perilli Buenos Aires: Corregidor, 2014.
}

\section{Julia Sabena / Universidad Nacional del Litoral - Universidad Nacional de Rosario - Conicet juliasabena@gmail.com}

La literatura latinoamericana busca su linaje desde, al menos, las independencias nacionales. Si el siglo xx nos deparó un caudal de textos en los que se catalogan los "modos de funcionamiento" (I3) del archivo latinoamericano, con la memoria como problema central — tesis de González Echevarría a la que se vuelve en varios momentos en Sombras de autor-, el fin de siglo y principios del XXI siguen trabajando en la construcción de un origen y una genealogía. El modo encontrado por un nutrido conjunto de narraciones es, según Carmen Perilli, la de «ficciones de autor». La autora sabe encontrar, en un panorama difuso de la literatura latinoamericana, puntos de religación en la «narrativa de escritores» (I4), tendencia a la que se orienta este amplio grupo de narraciones de las que se encarga de indagar: "mitos de autor, fábulas producidas en la medida en que la historia literaria se ve como artefacto literario, escritores y lectores como personajes, convertidos en artefactos culturales» (22).

La confección del propio linaje por parte del escritor es una operación que tiene una espesa tradición. Así como Dante se fabula bien acogido entre la «in- 
signe escuela» que conforman Homero, Horacio, Lucano y Ovidio, los autores que revisa Perilli elaboran una "ciudad letrada» en la que de una u otra manera se encuentran admitidos. Siéndole familiar el acervo crítico sobre los virreinatos latinoamericanos, retoma ese concepto ramiano para dar cuenta del trazado que imprimen los autores estudiados en sus novelas, quienes, en busca de una genealogía, acuden a historias de vida —o de muerte- de otros escritores o lectores. Ella se puebla, así, de ficciones biográficas que no se despegan de la autobiografía, cuyos elementos se hacen presentes y se entremezclan en las novelas, en una suerte de diálogo en el que ese trazado adquiere alguna representación sobre el presente de la enunciación.

El libro agrupa diferentes artículos aparecidos en revistas especializadas o capítulos de libros a través de esta clave interpretativa («textos acuciados por el destino de la literatura, donde los escritores fabulan una curiosa ciudad letrada» -9-) común a todos ellos, que modula rasgos particulares en cada uno. Las categorías teóricas y críticas despliegan un sólido aparato de lectura montado, esto es crucial, a partir de lo que los textos exigen, lejos de ciertas tendencias actuales que orientan lecturas forzadas de la literatura del continente en la consecución de ideas preconcebidas, ajenas, en general, a lo literario. La metodología se muestra, como en toda crítica sólida, sencilla y clara. Se parte de una intuición surgida de la lectura; se acota un corpus; se acude a la teoría y a la crítica en busca de herramientas potentes que permitan avanzar en la confirmación o refutación de la intuición y con ellas se procede al análisis.

Después de un brevísimo comentario sobre esa intuición, en tanto lectora y crítica, se despliega el recorrido del hilo que trazan estas sombras de autor, en una trama que gana densidad en el interior de cada obra analizada. El primer artículo, «Fijando sombras: una narrativa en busca de autor» se detiene en la idea más general, comentada arriba, y la presenta en contigüidad con la de González Echevarría que plantea a la literatura latinoamericana del siglo xx poblada de ficciones de archivo que «siguen buscando la clave de la cultura y la identidad latinoamericana» (I2). De este modo, la autora pasa revista a los diferentes modos de funcionamiento de ese archivo en algunas ficciones latinoamericanas de entre-siglos para ir perfilando los lineamientos generales del conjunto; da cuenta del concepto "vida de escritor» (22) y su relación con las biografías y autobiografías, su desarrollo en una sociedad más espectacular y globalizada; brinda los criterios de armado del corpus y deja asomar varias de las categorías que conforman el sustrato teórico crítico del abordaje: el «valor biográfico»(Bajtin), esencial para esta lectura, en el que se apoya la genealogía, no sólo es armado de la vida de otro sino que organiza también la propia; la idea de «mito» como habla naturalizada (Barthes); el diálogo entre autor y biografiado (personaje) que se establece en la biografía (Holroyd), se explica también a la «ficción de autor» como identidad inventada (Premat), entre otras.

El capítulo siguiente, «Sombras en una isla: José María Heredia y Ernest Hemingway», refiere al proceso identitario particular de Cuba en su literatura, del que 
participa Leonardo Padura revisando el archivo literario. Su biografía sobre José María Heredia deja al descubierto que toda historia literaria es producto de una ficción y se vale del relato de la vida de Heredia, figura del poeta cívico, para simbolizar su presente y su propia familia literaria, su «ciudad letrada» atravesada por la Revolución, e intentar delinear una salida para la contingencia histórica y política por parte de la literatura. Parte del mismo planteo observa la autora en otra novela de Padura, Adiós Hemingway, en la que la muerte del norteamericano (figura cara al régimen castrista) es asediada mientras se pone en cuestión el mito del escritor.

Similar mecanismo con diversos resultados despliega Perilli para el resto del corpus: el también cubano Pedro Juan Gutiérrez pone en el tapete el relato nacional en su Trilogía sucia de La Habana y Animal tropical (cuyo protagonista es Pedro Juan) y su novela sobre Graham Greene. El uso del mito de Asunción Silva por parte de Fernando Vallejo es aprovechado para el armado de su propia genealogía y la revisión del archivo literario colombiano: en la desmitificación de su admirado poeta modernista ofrece una «suerte de identidad nacional negativa» (6o), se debate entre el amor y odio a la Patria, e interpela al proceso mismo del relato literario, proliferación de decires y falsas garantías de verdad en documentos y testimonios. Una novela de Vallejo sobre otro mítico autor, Porfirio Barba Jacob; el mexicano Villoro y su fábula sobre López Velarde y la cultura mexicana; Carlos María Domínguez escribiendo sobre el dandy anarquista Roberto de las Carreras, en una reconstrucción de la "ciudad letrada» uruguaya no exenta de crítica cultural; Margo Glantz leyendo el «revés de los relatos maestros» (II9) en la historia de la Malinche y de las monjas conventuales mexicanas y construyendo, como el resto de los autores, su propio linaje —esta vez femenino-; y Roberto Bolańo, cuya poética se apoya en - y excede — estos mecanismos analizados, utilizados en «biografías apócrifas de escritores infames» (I37). Este último autor merece dos capítulos, "Cómo construir un escritor infame: Roberto Bolaño» y «La sombra del escritor: Benno Von Archimboldi», que cierran el volumen. No parece casualidad: la obra del chileno, repleta debiografía, dobles autobiográficos, reflexión sobre la literatura, sobre el archivo, abuso de intertextualidad, exige ser leída -o es la impresión que sabe dejar Perilli- desde el aparato construido por la autora.

El libro contiene una propuesta muy interesante para el abordaje de la literatura de los últimos veinte ańos en América Latina, ya que, con una mirada que no se limita a la Nación, y atenta al comentario estilístico y el estudio expresivo, se instala en esa persistente búsqueda e interroga a la literatura escuchando con atención lo que ésta tiene para decirle. 